\title{
Nutrition research priorities for the Third World
}

By P. R. Payne, Nutrition Policy Unit, Department of Human Nutrition, London School of Hygiene and Tropical Medicine, Keppel Street (Gower Street), London $W C \_E{ }_{7} H T$

For many people, the juxtaposition of the words 'research' and 'priorities' produces the reaction that these are to some extent imcompatible notions unless defined in rather special and restricted ways. Successful research, it is said, is essentially an activity dependent upon the stimulation of individuals, exposed perhaps quite by chance, to the impact of experience; the outcome being to a large degree unpredictable. But if it is such a chancy business, in what way does it make sense to define priorities? Of course, one can select individuals in terms of their background training, and known performance, and one can offer a selected range and type of experience situations, either in the field, or the laboratory. But there has always been very strong resistance to the notion that criteria for selection of individuals, or for the offer of different types of experience should be based on anything other than what is described as 'scientific merit'.

What this usually means in practice is a judgement by professional peers based on concensus views of what kinds of work constitute real contributions, and what areas of experience are likely to be most fruitful. The standards and criteria are therefore internal, in the sense of being generated by a professional group of say, nutritionists, or physicists or chemists, and are usually defended by describing them as purely technical in character, and thus free of any bias of a social or political nature. Indeed, other kinds of criteria are often rejected on the grounds that they might impede the progress of research by imposing constraints based, for example, on social priorities.

As an example of this, the report of the Inter-University Council (1977) on British Universities and Polytechnics and Overseas Development, vigorously rejects the notion of 'relevance' in research or in the setting of priorities for exchanges between UK and overseas universities. Instead, the Committee asserts that the value of overseas experience springs simply from mutual contact between individuals and groups of the highest level of academic excellence.

It is of course inconceivable that any group of people representing a profession, or acting as an advisory committee could produce a statement of research priorities which was not also a reflection of their own social and cultural values. The position that needs to be challenged therefore is that there exists a framework of scientific judgement which is value free, and will therefore yield an undistorted set of priorities.

What we should do in the future, particularly about Third World priorities is not quite so clear. If nutritionists in the UK assert priorities, they are in effect saying in the light of their own values and beliefs, what they feel would be most beneficial for other countries. 
I have devoted so much space to this opening discussion because I believe we are entering a period in which applied science in general, and some branches in particular, will be exposed to strong criticism with regard to their contribution to the developing countries. Thus Reddy (1978) suggests that the UN Conference on Science and Technology for Development next year will 'put science and technology on trial', accused not only of failing to assist development, but also of actually thwarting and distorting it.

A more specific example is contained in a recent report from the World Health Organization (WHO, I978) which is a frank commentary on the disastrous failure of traditionally organized medical services to meet the health needs of the poorer countries.

Just at the moment, nutrition is riding high. There is great interest in the contribution nutrition and food sciences could make to development, but this could rapidly turn sour.

Before going on to talk about where I think priorities should lie, it is instructive to make a brief comparison of the reports on research priorities of two officially constituted groups of experts. These are from the UK, the Agricultural Research Council/Medical Research Council (1974) report and from the USA, the more recent World Food and Nutrition Study, National Research Council (1977).

The UK Committee did not attempt to categorize Third World issues separately from those generally related to human nutrition, but did frequently identify problem areas as being of direct relevance. Table I shows how they classified priority areas, problem areas, and finally research topics. Table 2 shows the USA Committee's classification of high priority areas and suggested research topics.

\section{Table I. Some findings of the Agricultural Research Council/Medical Research Council committee}

Priorities for research in human nutrition

Monitoring the status of populations

Nutrition related diseases

Underlying principles

e.g. enzyme kinetics

protein turnover mechanisms of vitamin action trace element requirements

Nutrition and human

development

\section{Problem areas}

Food consumption and social aspects of nutrition

Nutrient requirements

Nutritional problems in public health

Faulty nutrition as a cause of disease

Problems of nutrition in the treatment and management of disease

Aspects of food quality
Suggested research topics

New techniques for measurement of food consumption Carbohydrate, fat and amino acid metabolism, mode of action of vitamins at the molecular level, protein turnover and energy costs of protein synthesis Establishing criteria of normality, quantifying effects of nutrition on growth, development and disease resistance

Protein-energy malnutrition Food safety, measuring protein quality, testing novel foods

-ARC/MRC (1974). 


\section{Table 2. Some findings of the World Food and Nutrition Study*}

High priority research areas

Nutrition-performance relations Role of dietary components Policies affecting nutrition Nutrition intervention programmes
Suggested research

Determine damage caused by various kinds and levels of malnutrition: effects of diet patterns on levels of human functioning.

Determine specific foods that best meet nutritional needs under differing circumstances: effects of individual nutrient levels, as consumed, on nutritional status.

Improve effects of full range of government policies: effects on nutrition of policies and practices usually formulated with no consideration of possible nutritional consequences.

Improve effects of direct intervention programmes: evaluate effectiveness of alternative programmes in reaching nutritional goals.

\section{-National Research Council (1977).}

The dissimilarities are interesting. The US report was much larger in scope, and was produced by thirty-two work groups each of which covered a range of disciplines, and drafts were very widely circulated internationally with requests for comment. There was a very strong representation of the social sciences, and this shows clearly in, for example, the identification of government policy and administration as a priority research area in its own right.

The UK report on the other hand lists research into underlying principles as a priority area. This generally means research into biochemical and physiological mechanisms, and frequently the report refers to problems at the molecular level as being important. In fact, one of its most obvious features is an insistent reductionism: a definition of basic research as an investigation of smaller and smaller scale components of biological systems. For example, in the section on vitamin A, after commenting that deficiency is a serious cause of ill health and blindness in poor countries (10000 cases/year in India) and that interventions such as massive dosage, fortification, and education are appropriate. Suggestions for research start with the statement that 'the most important single problem to be solved is the mode of action of vitamin $A$ at the molecular level'.

Underwood (1978) has argued that none of the three currently used methods for evaluation of vitamin A intervention programmes is sufficiently reliable for the purpose.

What both reports have in common is that priorities are mainly identified as areas of ignorance, i.e. it is what is not known or not understood by groups of scientists that primarily decides what they propose should be researched. In both cases, attempts were made to define general objectives for research, but in neither case was an explicit attempt made to explain the choice of areas or topics in terms of these objectives. Thus, for example, the US report identified Nutrition-performance relationships as first of the four nutrition priorities. Admittedly there are large gaps in our knowledge about nutrition and performance, although not for want of trying, but how exactly will greater knowledge help in 
reducing malnutrition? By stimulating action where there was none? By improving design of interventions?

If research priorities cannot be adequately defined in terms of the need simply to extend factual knowledge, what more do we need to do? Clearly, we need to relate the activity of exploring what things happen and what things are possible in the world, with a set of objectives which will help us to decide what things it is valuable to know more about. The fact that this paper is one of two which seek to distinguish between priorities for the UK and priorities for the Third World suggests that we need to articulate not just one general objective such as 'improving human welfare', but a number of aims which may not necessarily be fixed for all time, and which should in fact be the subject of open and continuing debate.

The participants in this debate should not be confined to any of the separate disciplines represented within nutrition, to the members of appointed committees, or to any other élite professional group. Still less should the inclusion of overseas concerns be brought about as the Inter-University Council suggests by international communication between similar groups. There must be a widening of participation and an increase in opportunities for exposure of researchers to social problems and conditions in poor countries as well as contacts between scientific opposite numbers.

I believe the Nutrition Society has a unique role to play in encouraging discussions about the aims of nutritional science, discussions which should specifically involve its overseas members. I believe also, that an important element in these discussions should be an analysis of the relationship between nutritionists considered as a social group, and the rest of society.

For my own purposes, I shall accept the statement of aims of the development process offered by Reddy ( $197^{8}$ ).

I. The satisfaction of basic human needs, material and non-material, starting with the needs of the neediest; to reduce inequalities between and within countries.

2. Endogenous self-reliance, to promote social participation and control.

3. Harmony with the environment, to sustain development over the long run.

The following areas of nutrition research seem most likely to contribute to furthering these aims; improving techniques for identifying those most in need of improved nutrition and characterizing and quantifying the nature of their needs, contributing to the analysis of causes of nutritional deprivation in such a way as to extend the means of their control by social participation and exploration of new possibilities for extending food resources, and identification of those innovations most likely to lead to materially and socially sustainable futures.

Three examples of research needs taken from these areas are:

I. Estimating the magnitude and trends in malnutrition. How big is the problem within countries and world-wide, and is it getting better or worse?

Estimates range from about $15 \%$ of poor country populations by Sukhatme (1961) to $75 \%$ by Reutlinger and Selowsky (1976). This is not merely of 
propaganda importance, the lower estimate would place food supply and income distributional needs well within the current capacities of most individual countries. The higher would imply the need for fairly massive interim food aid with all the disadvantages (for the recipients at least) of increased dependence and disincentives for self-reliance.

2. Malnutrition and infectious diseases. We need to develop methods for deciding in a variety of different situations, whether food availability (quantity or quality) or environmental disease hazards is the limiting factor, or whether both are determinants of malnutrition. We need some change of attitudes here as well as research; it should be just 28 rewarding to assist a community by showing that no special nutrition programme is necessary provided environmental hygiene is improved as it is to initiate a necessary change in food production and use.

3. Development of guide-lines for research in food science and agriculture which will lead to the orientation of new products towards the nutritional needs of the neediest, and which will contribute towards the reduction of social disparities rather than exacerbating them.

\section{REFERENCES}

Agricultural Rescarch Council/Medical Research Council (1974). Food and Nutrition Research. London: HMSO.

Inter-University Council (1977). British Universities and Polytechnics and Oterseas Development. London: Inter-University Council.

National Research Council (1977). World Food and Nutrition Study. Washington DC: National Academy of Sciences.

Reddy, A. K. N. (1978). New Scient. 80, No. $1126,270$.

Reutlinger, S. \& Selowsky, M. (1976). Malmutrition and Poverty: Magnitude and policy options. World Bank Staff Occasional Papers No. 23.

Sukhatme, P. V. (196r). Fl R. Statist. Soc. A $124,463$.

Underwood, B. A. (1978). Bull. Wld Hlth Org. 56, 4, 525.

WHO/UNICEF (1978). Primary Health Care. Geneva: WHO. 